OPEN ACCESS

Edited by:

Saskia Bindschedler,

Université de Neuchâtel, Switzerland

Reviewed by:

Baogang Zhang,

China University of Geosciences,

China

Juntao Wang,

Western Sydney University, Australia

*Correspondence:

Weijun Shen

shenweijun@gxu.edu.cn

Specialty section:

This article was submitted to

Terrestrial Microbiology,

a section of the journal

Frontiers in Microbiology

Received: 01 April 2021

Accepted: 30 July 2021

Published: 25 August 2021

Citation:

He J, Jiao S, Tan X, Wei H, Ma X, Nie Y, Liu J, Lu X, Mo J and Shen W

(2021) Adaptation of Soil Fungal Community Structure and Assembly to Long- Versus Short-Term Nitrogen

Addition in a Tropical Forest.

Front. Microbiol. 12:689674.

doi: 10.3389/fmicb.2021.689674

\section{Adaptation of Soil Fungal Community Structure and Assembly to Long- Versus Short-Term Nitrogen Addition in a Tropical Forest}

\author{
Jinhong He ${ }^{1}$, Shuo Jiao ${ }^{2}$ Xiangping Tan ${ }^{1}$, Hui Wei ${ }^{3}$, Xiaomin Ma ${ }^{1}$, Yanxia Nie', \\ Juxiu Liu' ${ }^{1}$, Xiankai Lu', Jiangming $\mathrm{Mo}^{1}$ and Weijun Shen ${ }^{4 *}$ \\ ${ }^{1}$ Center for Ecological and Environmental Sciences, South China Botanical Garden, Chinese Academy of Sciences, \\ Guangzhou, China, ${ }^{2}$ State Key Laboratory of Crop Stress Biology in Arid Areas, Shanxi Key Laboratory of Agricultural \\ and Environmental Microbiology, College of Life Sciences, Northwest A\&F University, Yangling, China, ${ }^{3}$ Department \\ of Ecology, College of Natural Resources and Environment, South China Agricultural University, Guangzhou, China, ${ }^{4}$ College \\ of Forestry, Guangxi University, Nanning, China
}

Soil fungi play critical roles in ecosystem processes and are sensitive to global changes. Elevated atmospheric nitrogen $(\mathrm{N})$ deposition has been well documented to impact on fungal diversity and community composition, but how the fungal community assembly responds to the duration effects of experimental $\mathrm{N}$ addition remains poorly understood. Here, we aimed to investigate the soil fungal community variations and assembly processes under short- (2 years) versus long-term (13 years) exogenous $\mathrm{N}$ addition $\left(\sim 100 \mathrm{~kg} \mathrm{~N} \mathrm{ha}^{-1} \mathrm{yr}^{-1}\right)$ in a $\mathrm{N}$-rich tropical forest of China. We observed that shortterm $\mathrm{N}$ addition significantly increased fungal taxonomic and phylogenetic $\alpha$-diversity and shifted fungal community composition with significant increases in the relative abundance of Ascomycota and decreases in that of Basidiomycota. Short-term N addition also significantly increased the relative abundance of saprotrophic fungi and decreased that of ectomycorrhizal fungi. However, unremarkable effects on these indices were found under long-term $\mathrm{N}$ addition. The variations of fungal $\alpha$-diversity, community composition, and the relative abundance of major phyla, genera, and functional guilds were mainly correlated with soil $\mathrm{pH}$ and $\mathrm{NO}_{3}{ }^{-}-\mathrm{N}$ concentration, and these correlations were much stronger under short-term than long-term $\mathrm{N}$ addition. The results of null, neutral community models and the normalized stochasticity ratio (NST) index consistently revealed that stochastic processes played predominant roles in the assembly of soil fungal community in the tropical forest, and the relative contribution of stochastic processes was significantly increased by short-term $\mathrm{N}$ addition. These findings highlighted that the responses of fungal community to $\mathrm{N}$ addition were durationdependent, i.e., fungal community structure and assembly would be sensitive to short-term $\mathrm{N}$ addition but become adaptive to long-term $\mathrm{N}$ enrichment.

Keywords: nitrogen addition, fungal community, stochastic processes, deterministic processes, tropical forest 


\section{INTRODUCTION}

As one of the major global change drivers, reactive nitrogen (N) from fertilizer application and fossil fuel combustion has increased by $120 \%$ over the past few decades (Galloway et al., 2004) and is expected to increase or at least not decrease rapidly in the near future ( $Y u$ et al., 2019; Wen et al., 2020). The excessive loading of reactive $\mathrm{N}$ has been found to have profound influences on terrestrial ecosystems, such as the reduction of forest soil respiration (Janssens et al., 2010), the attenuation of plant-microbe interactions (Wei et al., 2013), and the alteration of soil biogeochemical cycles ( $\mathrm{Lu}$ et al., 2011). Fungi play vital roles in the structural and functional dynamics of terrestrial ecosystems. For instance, saprotrophic fungi are the primary decomposers of plant litter and soil organic matter due to their relatively higher capability to degrade cellulose and lignin (Baldrian and Valášková, 2008; Schneider et al., 2012), and mycorrhizal fungi can shape plant community dynamics by affecting seed dispersal, seedling establishment, and intra/inter-specific interactions (Tedersoo et al., 2020). Previous studies suggested that experimental $\mathrm{N}$ addition or fertilization generally shifts the fungal community composition directly by affecting their nutrient supply and indirectly by altering edaphic conditions (Yang Y. et al., 2020; Cui et al., 2021). Different fungal guilds may exhibit different responses to $\mathrm{N}$ enrichment. For instance, the relative abundance and diversity of mycorrhizal fungi decreased, whereas that of saprotrophic fungi increased with experimental $\mathrm{N}$ addition (Weese et al., 2015; Morrison et al., 2016), thus resulting in the shifts of community composition. Therefore, knowledge of how soil fungal communities respond to $\mathrm{N}$ addition is critical for predicting ecosystem responses and for managing plant-fungi interactions under the context of global environmental changes and maintaining sustainable agriculture and forestry (Bissett et al., 2013; Dessaux et al., 2016).

More often, the effects of $\mathrm{N}$ enrichment on fungal biomass and diversity are related to the $\mathrm{N}$ rates and duration of application (Yang et al., 2019). Previous researches showed that shortterm exogenous $\mathrm{N}$ enrichment could reduce or increase soil fungal community diversity (Zhang $\mathrm{H}$. et al., 2018; Chen et al., 2020; Zhao et al., 2020), but other studies indicated that fungal communities had the potential to adapt to the long-term $\mathrm{N}$ addition (Entwistle et al., 2013; Freedman et al., 2015; Yan et al., 2021). Microorganisms are known for their capabilities of resistance and resilience to perturbations, but it should be noted that microbial communities are generally sensitive to environmental changes and can recover from disturbance across the time scales of days to years (Allison and Martiny, 2008; Li et al., 2014). However, we have limited knowledge on the duration effects of $\mathrm{N}$ addition, mainly because molecular approaches characterizing microbial diversity were not available for early long-term $\mathrm{N}$ addition experiments. Understanding the duration effects of exogenous $\mathrm{N}$ enrichment is therefore helpful for predicting the dynamic responses of fungal communities to future environmental changes.

It is now widely recognized that microbial community assembly is often determined by both deterministic and stochastic processes (Caruso et al., 2011; Nemergut et al., 2013; Zhao Z. et al., 2019). The deterministic processes mainly include selection via environmental filtering and biotic interactions (He C. et al., 2021; He Q. et al., 2021). The stochastic processes consider that microbial species dynamics are controlled by stochastic dispersal, ecological drift, and diversification (Vellend, 2010; Nemergut et al., 2013). Nitrogen enrichment can affect the processes underpinning fungal community assembly, but inconsistent results have been reported. For example, stochastic processes dominate under the fertilization treatment in cropland ecosystems (Shi et al., 2019; Li et al., 2021), whereas deterministic processes were found to have a larger relative importance with fertilization in plantation and grassland ecosystems (Chen et al., 2017; Guo et al., 2020). Moreover, $\mathrm{N}$ fertilization resulted in tightened network associations among fungal, bacterial, and protist communities in diverse agricultural soils (Zhao Z. et al., 2019), indicating an increased importance of deterministic biotic interactions in shaping microbiome. Contrastingly, $\mathrm{N}$ fertilization did not change the fungal community networks in a temperate grassland soil (Chen et al., 2020). The discrepancies of fungal assembly processes response to $\mathrm{N}$ enrichment may be ascribed to the $\mathrm{N}$ application rate, duration, ecosystem type, and fungal categories of analysis; however, existing studies were mainly carried out in cropland and grassland ecosystems. It remains of continued relevance to understand how the relative contributions of stochastic versus deterministic processes influence fungal community assembly under $\mathrm{N}$ enrichment in forest ecosystems.

In this study, we took advantage of an existing long-term ( $\sim 13$ years) $\mathrm{N}$ addition experiment in a $\mathrm{N}$-rich but phosphorus (P)-deficient tropical forest (Mo et al., 2006), and initiated a new $\mathrm{N}$ addition experiment [hereafter the short-term $(\sim 2$ years) experiment] beside the long-term $\mathrm{N}$ addition experiment $(\sim 2 \mathrm{~km}$ away) with similar plant community composition and edaphic conditions (Han et al., 2018). A previous study based on the two experiments revealed that associated functional microbes of $\mathrm{N}$ transformation could adapt to long-term $\mathrm{N}$ addition to prevent $\mathrm{N}$ losses (Han et al., 2018). For this study, we took soil samples from the two experimental sites, and assessed the fungal diversity and community composition through Illumina Hiseq sequencing of internal transcribed spacer (ITS) region. Additionally, we used the null-based statistical framework, neutral community model, and the normalized stochasticity ratio (NST) index to quantify the relative contributions of deterministic and stochastic processes in shaping the fungal community. Accordingly, we hypothesized that (i) the short-term $\mathrm{N}$ addition would impose significant impacts on soil fungal diversity and composition, and the effects of long-term $\mathrm{N}$ addition would be slight; (ii) stochastic processes would dominate at the short-term site since it improves soil $\mathrm{N}$ availability for fungi, whereas deterministic processes would be prevalent at the long-term site since longterm excessive $\mathrm{N}$ inputs would create a stressful environment for fungal community (Wang et al., 2018); (iii) both the short- and long-term $\mathrm{N}$ additions would change the network structures of the soil fungal community, and a more clustered network structure would be observed at the long-term site 
since it creates a more stressful environment that selects more adaptive fungal guilds.

\section{MATERIALS AND METHODS}

\section{Site Description}

The long- and short-term $\mathrm{N}$ addition experiments were established in Dinghushan Biosphere Reserve (DHSBR) in the city of Zhaoqing, Guangdong province of south China $\left(112^{\circ} 10^{\prime}\right.$ $\left.\mathrm{E}, 23^{\circ} 10^{\prime} \mathrm{N}\right)$. The reserve lies in a tropical moist forest region and covers about 1,155 ha with a monsoon climate. The mean annual precipitation is $1,748 \mathrm{~mm}$, mainly concentrated from April to September, with only a small part falling from October to March. The mean annual temperature is $21.0^{\circ} \mathrm{C}$, with a monthly average temperature ranging from $12.6^{\circ} \mathrm{C}$ in January to $28.0^{\circ} \mathrm{C}$ in July. The atmospheric $\mathrm{N}$ deposition in the reserve had reached $49.78 \mathrm{~kg} \mathrm{~N} \mathrm{ha}^{-1} \mathrm{yr}^{-1}$ in 2015-2016 (Zhou et al., 2018). The forest type is evergreen broadleaf forest and it has been characterized as $\mathrm{N}$-rich but P-limited in previous studies (Mo et al., 2006; Lu et al., 2018). The dominant tree species included Castanopsis chinensis Hance, Machilus chinensis (Champ. Ex Benth.) Hemsl., Schima superba Chardn. et Champ., Cryptocarya chinensis (Hance) Hemsl., Cryptocarya concinna Hance, and Randia canthioides Champion ex Bentham. The forest ages are approximately 400 and 100 years for the long- and short-term sites, respectively.

\section{Experimental Design and Soil Sampling}

The long-term experiment was established in 2002, and $\mathrm{N}$ addition started in July 2003 with a monthly spraying ammonium nitrate $\left(\mathrm{NH}_{4} \mathrm{NO}_{3}\right)$ solution (Mo et al., 2006). Three $10 \times 20 \mathrm{~m}^{2}$ plots were assigned for $\mathrm{N}$ addition $(\mathrm{N}$; ambient $+100 \mathrm{~kg} \mathrm{~N}$ $\mathrm{ha}^{-1} \mathrm{yr}^{-1}$ ), and three paired plots were designed as control (C; ambient $\mathrm{N}$ deposition). For each $\mathrm{N}$ addition plot, the required $\mathrm{NH}_{4} \mathrm{NO}_{3}$ was weighed, dissolved in $20 \mathrm{~L}$ of water, and sprayed evenly below the canopy using a backpack sprayer. Control plots received $20 \mathrm{~L}$ of water, which is equivalent to an increase of $1.2 \mathrm{~mm} \mathrm{yr}^{-1}$ precipitation. The short-term experiment was established in October 2013; $\mathrm{N}$ addition began in September 2014, with 0 and $105 \mathrm{~kg} \mathrm{~N} \mathrm{ha}^{-1} \mathrm{yr}^{-1} \mathrm{NH}_{4} \mathrm{NO}_{3}$ for control (C) and $\mathrm{N}$ addition $(\mathrm{N})$ treatments, respectively. A total of six (three replicates per treatment $\times$ two treatments) randomly scattered plots $\left(15 \mathrm{~m} \times 15 \mathrm{~m}\right.$ in area) were set up. The required $\mathrm{NH}_{4} \mathrm{NO}_{3}$ was dissolved in $30 \mathrm{~L}$ water and sprayed below the canopy monthly in each $\mathrm{N}$ addition plot. The control plots received an equivalent volume of water only, which corresponded to an extra $1.6 \mathrm{~mm}$ of precipitation that occurred each year.

Surface soil samples $(0-20 \mathrm{~cm})$ were collected four times from each plot in the wet (July 2015 and 2016) and dry (January 2016 and 2017) seasons. Within each plot, samples were randomly taken using a soil core $(\Phi 5 \mathrm{~cm})$ at six spots to form a composite sample for analysis, which resulted in 24 soil samples for each site in the 2 years. Visible roots and plant residues were removed from all samples, which were then sieved through a $2-\mathrm{mm}$ mesh. The sieved samples were divided into two groups. One group was used to determine soil properties, and the other was kept at $-80^{\circ} \mathrm{C}$ for subsequent DNA extraction and microbial community analyses.

\section{Measurement of Soil Properties}

Soil water content (SWC) was measured gravimetrically using $10 \mathrm{~g}$ of fresh soil by oven-drying at $105^{\circ} \mathrm{C}$ for $24 \mathrm{~h}$. Soil $\mathrm{pH}$ was determined in a 1:2.5 air-dried soil:water suspension (w:v) using a pH meter (F-71G, LAQUA, HORIBA, Japan). Soil ammonium $\mathrm{N}\left(\mathrm{NH}_{4}{ }^{+}-\mathrm{N}\right)$ and nitrate $\mathrm{N}\left(\mathrm{NO}_{3}{ }^{-}-\mathrm{N}\right)$ were extracted by $1 \mathrm{M} \mathrm{KCl}$ from $20 \mathrm{~g}$ fresh soil samples and detected using the indophenol blue and dual wavelength $(220 \mathrm{~nm}$ and $275 \mathrm{~nm}$ ) colorimetric methods (UV-6000, China), respectively. Soil total organic carbon (TOC) was analyzed using an external heating method with concentrated sulfuric acid and potassium dichromate $\left(\mathrm{H}_{2} \mathrm{SO}_{4}-\mathrm{K}_{2} \mathrm{Cr}_{2} \mathrm{O}_{7}\right)$. To examine the contents of soil total $\mathrm{N}(\mathrm{TN})$ and total phosphorus (TP), semi-micro Kjeldahl digestion was carried out followed by indophenol blue and molybdenum antimony blue colorimetric methods, respectively. Soil dissolved organic carbon (DOC) and $\mathrm{N}$ (DON) were extracted with $0.5 \mathrm{M} \mathrm{K}_{2} \mathrm{SO}_{4}$ solution and measured using a TOC analyzer (Shimadzu TOC-VCSH Analyzer, Kyoto, Japan).

\section{Soil DNA Extraction and Sequencing}

Total DNA from soil was extracted using the PowerSoil ${ }^{\circledR}$ DNA Isolation Kit (MoBio Laboratories Inc., Carlsbad, CA, United States) according to the manufacturer's instructions. The extracted DNA was examined for quantity and quality using a Nanodrop 2.0 spectrophotometer (Thermo Fisher Scientific, Carlsbad, CA, United States). The paired primers ITS3-F ( $5^{\prime}$-GCATCGATGAAGAACGCAGC-3') and ITS4-R (5'TCCTCCGCTTATTGATATGC-3') were used to amplify the ITS2 region in the fungal rRNA operon (White et al., 1990). The PCR and tag-encoded high-throughput sequencing of the ITS2 were performed using the Illumina HiSeq platform (PE 250) (Guangdong Magigene Biotechnology Co., Ltd., Guangzhou, China).

\section{Sequence Processing and Bioinformatics}

The raw sequences were cleaned to ensure high-quality data; the reads with short sequences $(<200 \mathrm{bp})$, barcodes, and poly bases etc. were removed using the Fastp ${ }^{1}$ (V0.14.1) and cutadapt ${ }^{2}$ (Martin, 2011; Chen et al., 2018). The high-quality pairedend reads were then merged by USEARCH ${ }^{3}$ (V10.0.240) with a minimal overlap of $16 \mathrm{bp}$. Then the sequences were split into operational taxonomic units (OTUs) through the UPARSE pipeline, which performed chimera filtering and OTU clustering simultaneously, based on a $3 \%$ dissimilarity level. OTUs with fewer than two sequences were removed, and the representative sequence of each OTU was assigned to fungal taxonomic lineages by comparison with the UNITE database ${ }^{4}$ (V7.1). All the non-fungal OTUs were removed before downstream analyses.

\footnotetext{
${ }^{1}$ https://github.com/OpenGene/fastp

${ }^{2}$ https://github.com/marcelm/cutadapt/

${ }^{3}$ http://www.drive5.com/usearch/

${ }^{4}$ http://unite.ut.ee
} 
Eventually, to compensate for the uneven sequencing efforts of different samples, the OTU table was randomly subsampled to obtain the same sequence number $(61,292)$ for all the fungal data samples using the vegan package in $\mathrm{R}^{5}$ (V3.6.1).

We classified the fungal OTUs into functional groups according to the FUNGuild database (Nguyen et al., 2016). The taxa with confidence levels "highly probable" or "probable" and unique trophic guilds which belong to saprotrophic fungi, pathogenic fungi, or ectomycorrhizal (EcM) fungi were selected for further analyses.

\section{Phylogenetic Community Assembly}

The phylogenetic signals were assessed for the control and $\mathrm{N}$ addition treatments at each site to test whether fungal community responses to $\mathrm{N}$ addition was phylogenetically conserved. Phylogenetic correlogram was applied to test the phylogenetic signals and measured by the "mantel.correlog" function in the vegan package. The assembly processes of fungal community were evaluated using a null model analysis (Stegen et al., 2012, 2015; Dini-Andreote et al., 2015). Accordingly, ecological processes, which were classified into deterministic processes (e.g., variable and homogeneous selections) or stochastic processes (dispersal limitation, homogenizing dispersal, and undominated), were evaluated by $\beta$-nearest taxon index ( $\beta \mathrm{NTI})$

${ }^{5}$ http://www.r-project.org/ in combination with Raup-Crick metric (Bray-Curtis-based Raup-Crick, RC bray) (Stegen et al., 2012, 2013, 2015; Zhou and Ning, 2017). Based on Stegen et al. (2012), $\beta$ NTI $>2$ (or $\beta$ NTI $<-2$ ) between a pair of samples means the significantly higher (lower) phylogenetic turnover than expected (null distribution), indicating the predominance of variable selection (or homogeneous selection). Subsequently, the $\mathrm{RC}_{\text {bray }}$ was calculated to estimate the pairwise comparisons with $|\beta \mathrm{NTI}|$ $<2$. The percentage of homogeneous dispersal was quantified as the fraction of pairwise comparisons with $|\beta \mathrm{NTI}|<2$ and $\mathrm{RC}_{\text {Bray }}<-0.95$, while the dispersal limitation was quantified as the fraction of the pairwise comparisons with $|\beta \mathrm{NTI}|<2$ and $\mathrm{RC}_{\text {bray }}>0.95$. Finally, the remaining fractions $(|\beta \mathrm{NTI}|<2$ and $\left|\mathrm{RC}_{\text {bray }}\right|<0.95$ ) were treated as undominated processes (Stegen et al., 2015; Zhou and Ning, 2017).

To further quantify the contributions of stochastic (neutral) processes to fungal community structure under different $\mathrm{N}$ treatments, a normalized stochasticity ratio (NST) and a Sloan neutral community model were applied (Sloan et al., 2006; Ning et al., 2019). The NST, an index developed with 50\% as the boundary point between more deterministic $(<50 \%)$ and more stochastic ( $>50 \%$ ) assembly, was quantified using a pipeline based on the phylogenetic distance ${ }^{6}$. The Sloan neutral community model was fitted using the $\mathrm{R}$ script reported by

${ }^{6}$ http://ieg3.rccc.ou.edu:8080/

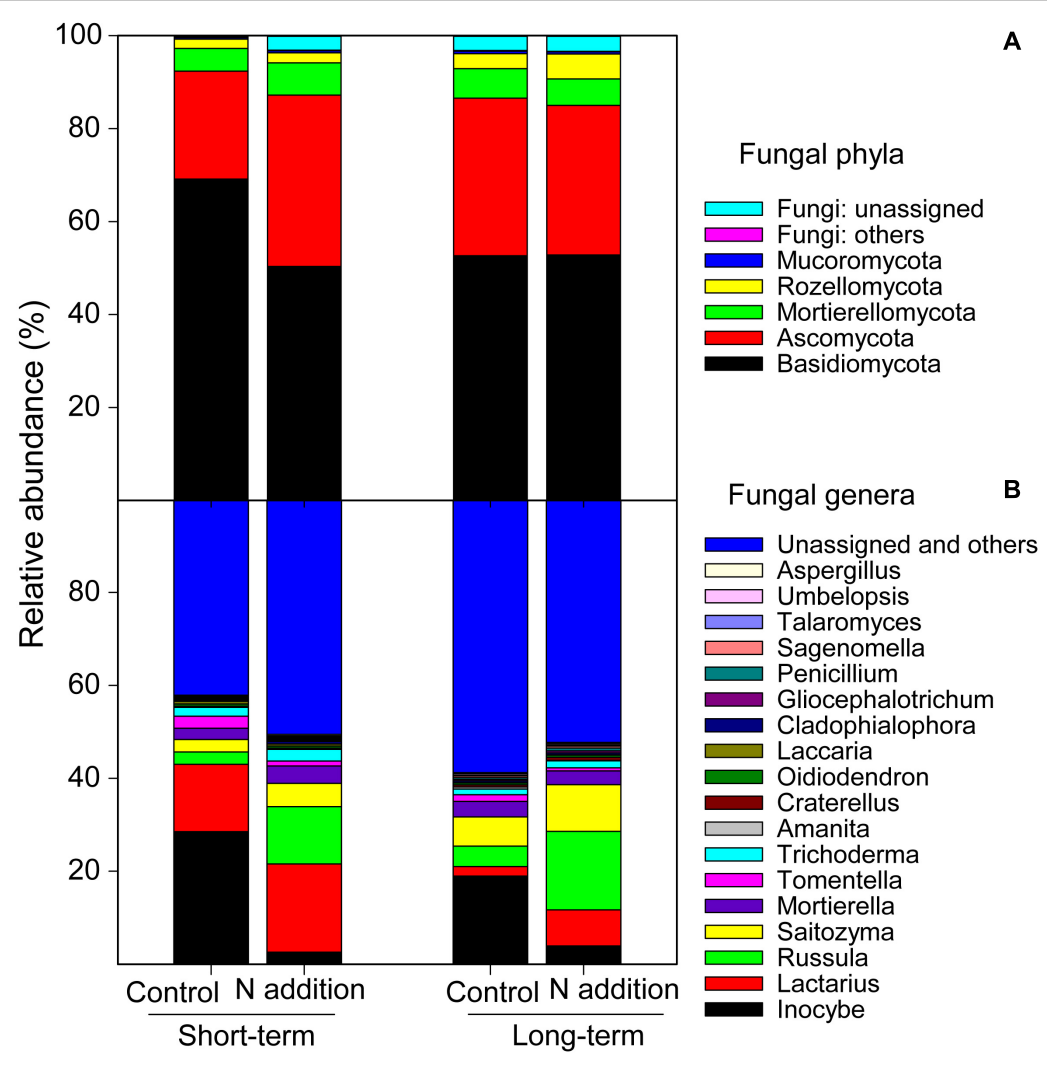

FIGURE 1 | Relative abundance of major soil fungal phyla (A) and genera (B) at the short- and long-term N addition sites. Phyla and genera with relative abundance $>0.2 \%$ are included. 
Barnes et al. (2016). $R^{2}$ indicates the fit of the parameter based on nonlinear least-squares fitting.

\section{Co-association Networks of Fungal Community}

Microbial linkage is one of the main drivers that contribute to the deterministic process of community assembly. To estimate the interspecies linkage within the fungal community across the control and $\mathrm{N}$ treatments at each site, co-association networks were constructed based on the Random Matrix Theory (RMT) using the Molecular Ecological Network Analysis Pipeline ${ }^{7}$ (Deng et al., 2012). Briefly, fungal OTU table was square roottransformed and then split into four sub-datasets according to duration and rate of $\mathrm{N}$ addition. For each sub-dataset, only those nodes detected in more than half of the total samples (majority rule) were kept for subsequent network construction. More information on theories, algorithms, pipeline structures,

${ }^{7}$ http://ieg4.rccc.ou.edu/mena and procedures can be found in references (Zhou et al., 2011; Deng et al., 2012). Network visualization was conducted using the interactive platform Gephi (WebAtlas, Paris, France). The "randomize the network structure and then calculate network" function was run to compare the properties of the empirical and randomly generated networks. The topological roles of each node in the network were determined by the threshold values of within-module connectivity $(\mathrm{Zi})$ and among-module connectivity $(P i)$ as proposed by Guimerà and Amaral (2005) in each network. Network hubs $(Z i>2.5$ and $P i>0.62)$, module hubs $(Z i>2.5$ and $P i<0.62)$, and connectors $(Z i<2.5$ and $\mathrm{Pi}>0.62)$ were termed keystone network topological features, and thus the OTUs associated with these nodes were defined as keystone species (Zhou et al., 2011; Deng et al., 2012).

\section{Statistical Analyses}

The phylogenetic $\alpha$-diversity was calculated with the picante package in R. The taxonomic $\alpha$-diversity (Richness and Shannon diversity index) was calculated by USEARCH. Three-way analysis
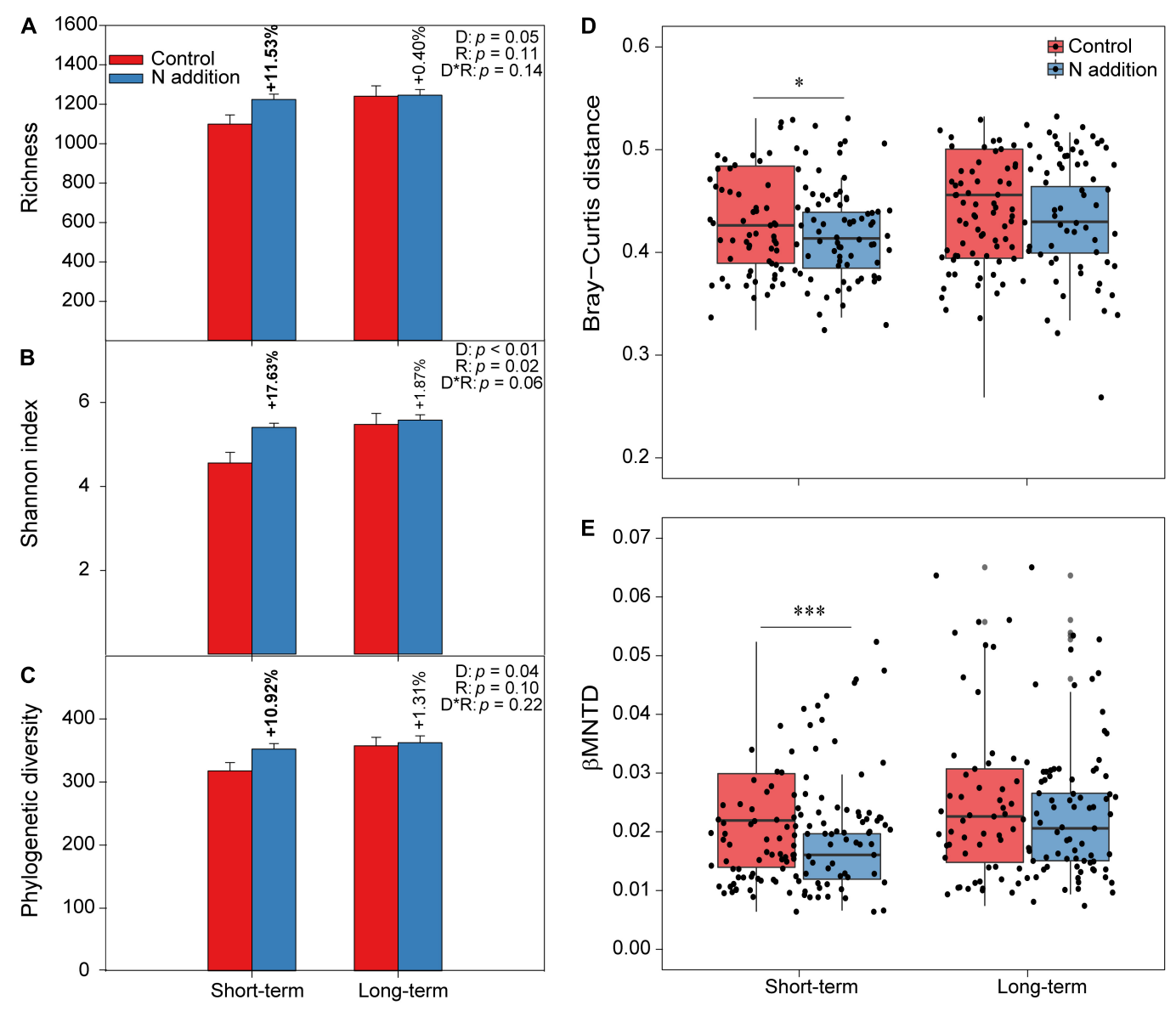

FIGURE 2 | The varations of fungal $\alpha$-diversity and community composition under short- and long-term $\mathrm{N}$ additions. (A-C) The varaitions of fungal $\alpha$-diversity under $\mathrm{N}$ addition are indicated by Student's $t$-test at the short- and long-term sites, respectively. The bold numbers denote the significantly differences ( $p<0.05)$ of fungal $\alpha$-diversity between control and $\mathrm{N}$ addition at each site. The insert texts indicate the effects of duration (D), rate (R) of $\mathrm{N}$ addition, and their interactions on fungal $\alpha$-diversity detected by two-way ANOVA. (D,E) The boxplots show community dissimilarities between control and $\mathrm{N}$ addition at the short- and long-term sites based on Bray-Curtis distance and $\beta$ MNTD, respectively $\left({ }^{*} p<0.05\right.$; ${ }^{* * *} p<0.001$; Wilcoxon rank-sum test). 
of variance (ANOVA) was used to evaluate the effects of the duration, rate, and season of $\mathrm{N}$ addition and their interactions on fungal taxonomic and phylogenetic $\alpha$-diversity. As the results showed that season had no significant effect on fungal $\alpha$-diversity, we considered the seasons as the replicates for downstairs analysis (Supplementary Table 1). Therefore, two-way ANOVA was performed to analyze the effects of duration, rate of $\mathrm{N}$ addition and their interactions on soil properties, fungal $\alpha$-diversity, and the relative abundance of major phyla, genera, and functional guilds. Student's $t$-test was used to assess the differences of aforementioned parameters between the control and $\mathrm{N}$ addition treatments in the short- and long-term sites, respectively. Before two-way ANOVA and Student's $t$-test were performed, the data were checked for normality (Shapiro test) and homoscedasticity (Bartlett test). If the datasets were not normal or homoscedastic, they were subjected to the Box-Cox transformation, ensuring that they met the assumptions of these tests. Linear regression models were used to express the correlations between soil properties and community variables, such as $\alpha$-diversity and relative abundance of major phyla, genera, and functional guilds.
The multivariate permutational analysis of variance (PERMANOVA) was conducted to analyze the variances in taxonomic (based on Bray-Curtis distance) and phylogenetic (based on beta mean nearest taxon distance; $\beta M N T D$ ) community composition and visualized by non-metric multidimensional scaling (NMDS). Analysis of similarities (ANOSIM) with 999 permutations based on Bray-Curtis dissimilarity and BMNTD was conducted to identify differences in OTU composition within and between treatments. The potential relationships between environmental variables and fungal taxonomic and phylogenetic community composition were assessed using constrained analysis of principal coordinates (CAP) analysis based on the "capscale" function of the vegan package in R. The significantly environmental factors were selected using "envfit" function of the vegan package with 999 random permutations. The variables that displayed significant effects $(p<0.05)$ were included in the ordination plot. To help reveal the variation in species composition of the fungal community, the Levins' niche breadth (Bcom) index (Levins, 1968) was determined using the "niche.width"

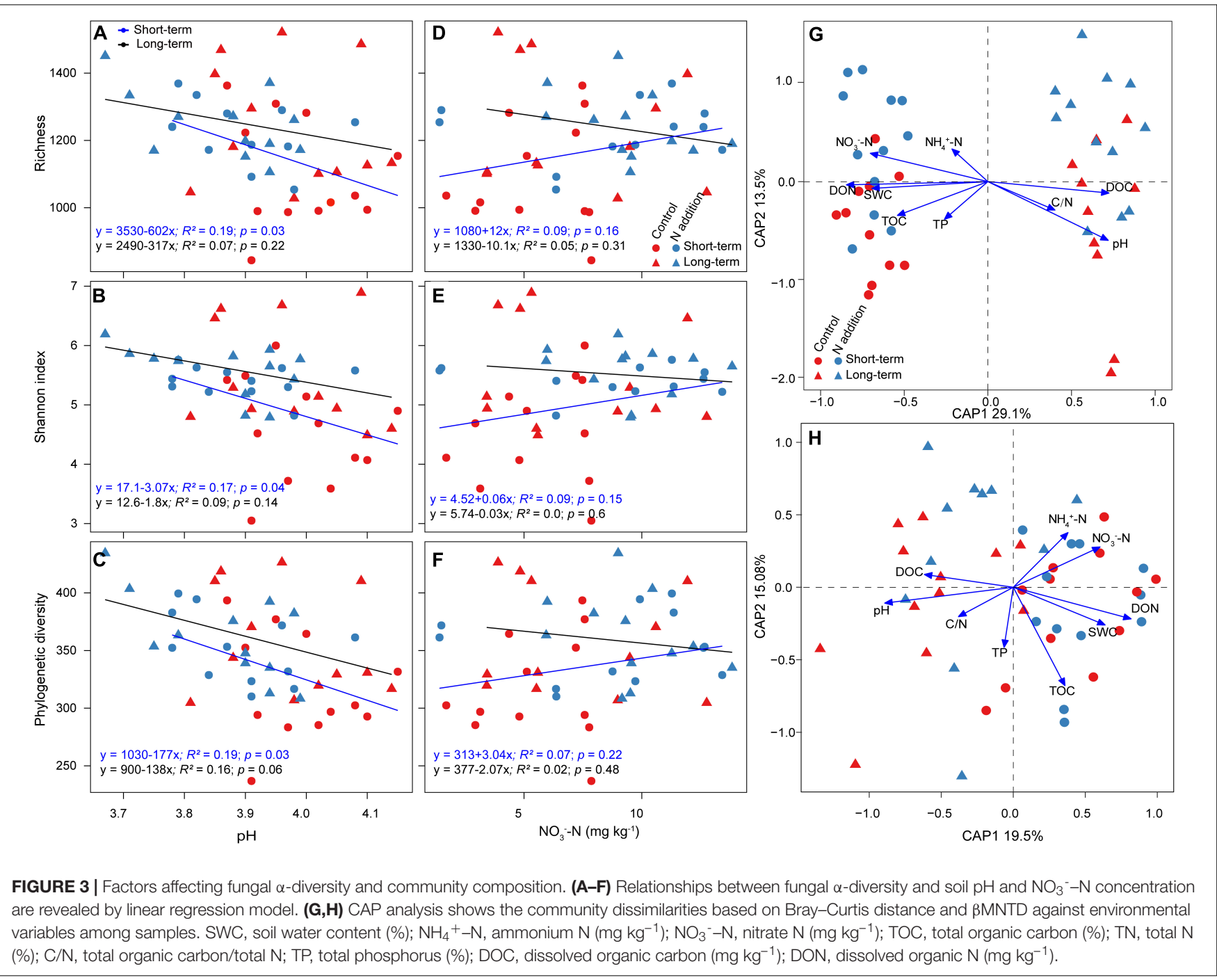


function in the spaa package in R. All the statistical analyses were performed in $\mathrm{R}$.

\section{RESULTS}

\section{Responses of Soil Physicochemical Properties to N Addition}

Of all the soil physicochemical parameters measured, only the soil $\mathrm{pH}$ and $\mathrm{NO}_{3}{ }^{-}-\mathrm{N}$ concentration were significantly affected by $\mathrm{N}$ addition (Student's $t$-test, $p<0.05$; Supplementary Table 2). Specifically, soils from both sites were strongly acidic with an average $\mathrm{pH}$ of 3.93, and $\mathrm{N}$ addition significantly decreased the soil pH by 0.1 unit at both sites $(p<0.05)$. Nitrogen addition also significantly increased the soil $\mathrm{NO}_{3}{ }^{-}-\mathrm{N}$ concentration by $56.11 \%$ at the short-term site, while only slightly (by $33.14 \%, p>0.05$ ) increased at the long-term site.

\section{Responses of Fungal Diversity and Community Composition to N Addition}

After a series of qualified and filtered steps, 2,942,016 sequences were retained and clustered into 4,672 fungal OTUs. Of all the samples, a total of $96.8 \%$ of the sequences could be assigned into 11 phyla and 261 genera (Figure 1). At the phylum level, Basidiomycota was predominant, followed by Ascomycota. The relative abundance of both phyla was significantly impacted by $\mathrm{N}$ addition and differed significantly between the long- and short-term sites $(p<0.05$; the insert text in Supplementary Figures 1A,B). At the short-term site, $\mathrm{N}$ addition significantly decreased the relative abundance of Basidiomycota by $27.19 \%$, but significantly increased that of Ascomycota by 58.82\% (Supplementary Figures 1A,B). However, the relative abundances of these phyla were not significantly affected by the long-term $\mathrm{N}$ addition $(p>0.05)$. At the genera level, the four dominant taxa were Inocybe, Lactarius, Russula, and Saitozyma representing $13.5 \%, 10.8 \%, 9.1 \%$, and $6.0 \%$ of all sequences, respectively (Figure 1B and Supplementary Figures 1C-F). At both sites, the $\mathrm{N}$ addition decreased the relative abundance of Inocybe (by $90.93 \%$ and $79.32 \%$ at short- and long-term sites, respectively) but increased that of Russula (by $368.04 \%$ and $283.98 \%$ at short- and long-term sites, respectively), Lactarius (by $30.47 \%$ and $282.31 \%$ at short- and long-term sites, respectively), and Saitozyma (by $87.13 \%$ and $60.44 \%$ at short- and long-term sites, respectively). At the functional guild level, approximately $43.4 \%$ sequences were categorized into EcM fungi, and the shortterm $\mathrm{N}$ addition significantly decreased the relative abundance of this group by $26.13 \%$ (Supplementary Figure 2A). Nevertheless, only $3.5 \%$ of sequences were classified as saprotrophic fungi, and the short-term $\mathrm{N}$ addition significantly increased the relative abundance of this group (Supplementary Figure 2B).

The two-way ANOVA indicated that the fungal taxonomical and phylogenetic $\alpha$-diversity was significantly influenced by the duration of $\mathrm{N}$ addition $(p<0.05$; the insert text in Figures 2A-C). Specifically, the three fungal $\alpha$-diversity indices (Richness, Shannon, and phylogenetic diversity) increased significantly (by more than $10 \%$ ) at the short-term $\mathrm{N}$ addition site $(p<0.05)$, while they were not significantly altered by the $\mathrm{N}$ addition at the long-term site. Moreover, the PERMANOVA indicated that the duration, rate of $\mathrm{N}$ addition, and their interactions significantly shaped the fungal community composition $(p<0.05$; the insert text in the top right corner of Supplementary Figure 3A). Specifically, the soil fungal community could be distinctly separated by short- and longterm $\mathrm{N}$ additions based on the Bray-Curtis distance metric by NMDS plots. In addition, the dissimilarity of the soil fungal community was significantly decreased by short-term $\mathrm{N}$ addition (Figure 2D). When considering the variation in phylogenetic community composition (based on $\beta$ MNTD), the duration of $\mathrm{N}$ addition significantly changed the fungal phylogenetic community composition; $\mathrm{N}$ addition significantly decreased $\beta M N T D$ at the short-term site, while significant changes were not found at the long-term site (Figure 2E and Supplementary Figure 3B). Moreover, fungal community in $\mathrm{N}$ addition soils had a higher habitat niche breadth than that in control soils at both sites (Supplementary Figure 4).

\section{Factors Affecting Fungal Diversity and Community Composition Under N Addition}

The linear regression indicated that the relative abundance of major functional guilds, phyla, and genera was mainly correlated with soil $\mathrm{pH}$ and $\mathrm{NO}_{3}{ }^{-}-\mathrm{N}$ concentration, and the correlations were much stronger at the short-term than long-term site (Supplementary Figures 5, 6). The relative abundance of EcM fungi and Basidiomycota was significantly positively correlated with soil $\mathrm{pH}$, and that of saprotrophic fungi and Ascomycota was significantly negatively correlated with $\mathrm{pH}$ at the short-term site, while these correlations were not significant at the longterm site. The soil $\mathrm{pH}$, not $\mathrm{NO}_{3}{ }^{-}-\mathrm{N}$ concentration, was the dominant driver to predict the variations of fungal richness, Shannon index, and phylogenetic diversity (Figures $\mathbf{3 A - F}$ ). The

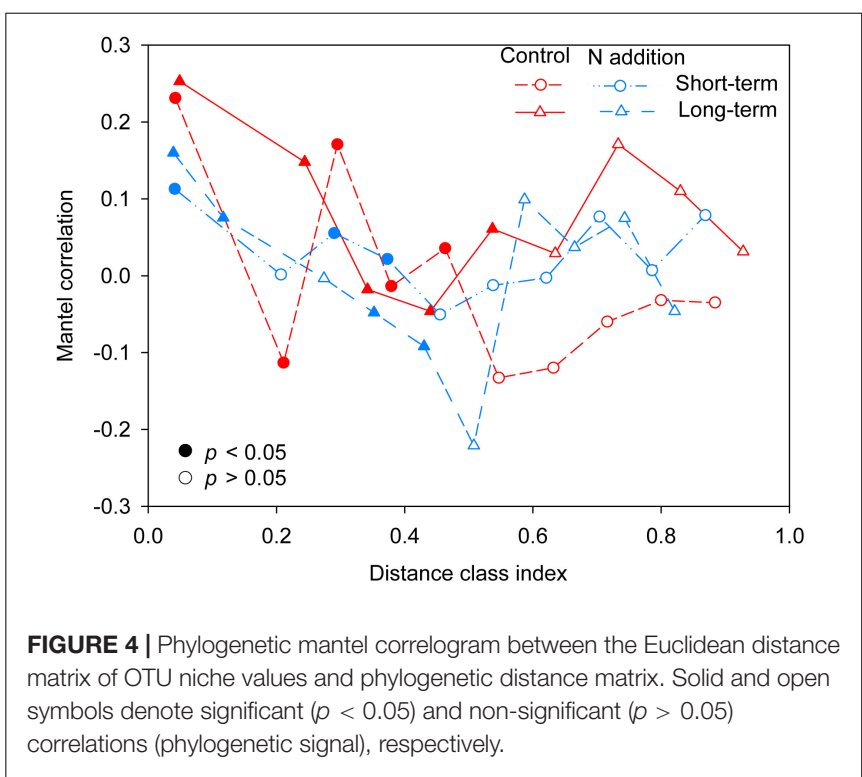




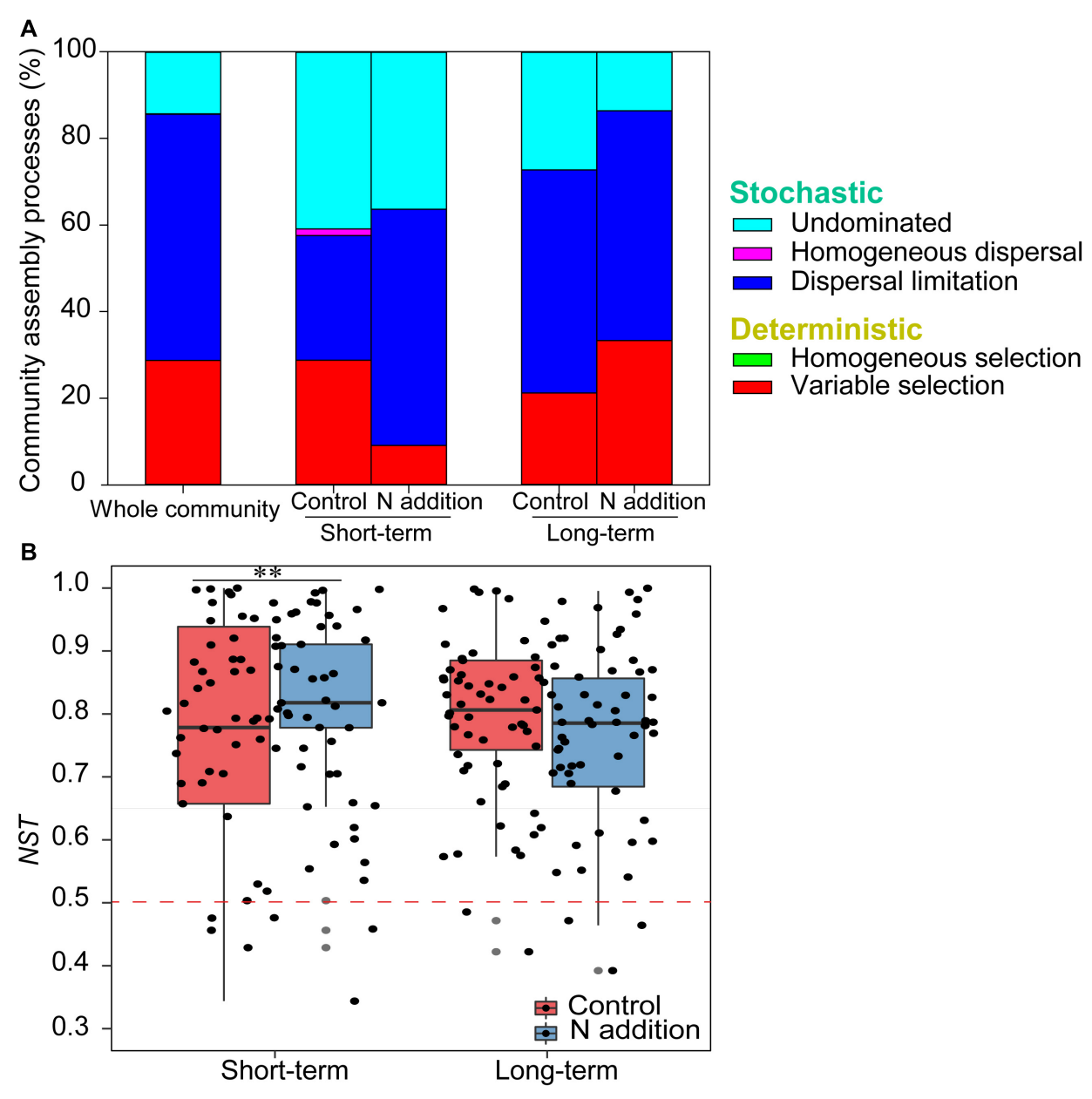

FIGURE 5 | The assembly processes in shaping fungal community. (A) The relative contributions (\%) of the five community assembly processes. (B) Boxplot shows the variation in NST under control and $\mathrm{N}$ addition at the short- and long-term sites (** $p<0.01$; Wilcoxon rank-sum test).

aforementioned $\alpha$-diversity indices were negatively correlated with soil $\mathrm{pH}$, and the correlations were more significant at the short-term than the long-term site. The CAP analysis also revealed that soil $\mathrm{pH}$ was the most important variable for the shifts of fungal taxonomic and phylogenetic community composition, and soil nutrients (such as DON, DOC, and $\mathrm{NO}_{3}{ }^{-}$ $\mathrm{N}$ ) were also important for fungal community composition (Figures 3G,H and Supplementary Table 3).

\section{Responses of Fungal Assembly Processes to N Addition}

The mantel correlogram showed significant phylogenetic signals across relatively short phylogenetic distances for the four subcommunities ( $p<0.05$, Figure 4), indicating that the fungal community in response to $\mathrm{N}$ enrichment are phylogenetically conserved and that the closely related species in the fungal community exhibited more similar ecological preferences to the environmental variables. Null model analysis revealed that stochastic processes mainly governed fungal community dynamics in the whole community and the four sub-communities
(Figure 5A). In the sub-communities, the relative contribution of stochasticity was increased by short-term $\mathrm{N}$ addition from $71.2 \%$ (control) to $90.9 \%$ ( $\mathrm{N}$ addition), while it was slightly decreased by long-term $\mathrm{N}$ addition from $78.8 \%$ (control) to $66.7 \%$ ( $\mathrm{N}$ addition). The NST results also showed the fungal community was predominately governed by stochastic processes (NST $=81.8 \%$ and $82.7 \%$ for the control treatment at the shortand long-term sites and $89.0 \%$ and $79.2 \%$ for the $\mathrm{N}$ addition treatment at the short- and long-term sites, respectively). Specifically, the NST increased significantly by short-term $\mathrm{N}$ addition $(p<0.01)$ but decreased slightly by long-term $\mathrm{N}$ addition (Figure 5B). The neutral model explained a large fraction $\left(R^{2}>0.5\right)$ of the variability in the occurrence frequency of the fungal community, with more than $80 \%$ of species having frequencies within predicted ranges (Supplementary Figure 7).

\section{Responses of Fungal Co-association Patterns to N Addition}

After data filtration, the remaining 405, 451, 369, and 461 OTUs were used to construct networks for the four sub-communities 
TABLE 1 | Detailed topological properties of the empirical and random networks of fungal community in soils under control and $\mathrm{N}$ addition at the short- and long-term sites, respectively.

\begin{tabular}{|c|c|c|c|c|}
\hline \multirow[t]{2}{*}{ Network index } & \multicolumn{2}{|c|}{ Short-term site } & \multicolumn{2}{|c|}{ Long-term site } \\
\hline & Control & $\mathbf{N}$ addition & Control & $\mathbf{N}$ addition \\
\hline \multicolumn{5}{|l|}{ Empirical networks } \\
\hline Total nodes & 405 & 451 & 369 & 461 \\
\hline Total links & 596 & 638 & 630 & 770 \\
\hline Positive links (\%) & 65.94 & 55.96 & 72.06 & 65.58 \\
\hline Negative links (\%) & 34.06 & 44.04 & 27.94 & 34.42 \\
\hline Similarity threshold (St) & 0.81 & 0.81 & 0.85 & 0.82 \\
\hline$R^{2}$ of power-law & 0.848 & 0.894 & 0.91 & 0.805 \\
\hline Average connectivity (avgK) & 2.943 & 2.829 & 3.415 & 3.341 \\
\hline Average clustering coefficient (avgCC) & 0.159 & 0.149 & 0.152 & 0.122 \\
\hline Average path distance (GD) & 7.55 & 8.589 & 5.803 & 7.662 \\
\hline Modularity (module no.) & $0.792(50)$ & $0.825(48)$ & $0.678(49)$ & $0.781(40)$ \\
\hline Diameter & 21 & 22 & 14 & 24 \\
\hline Density (D) & 0.007 & 0.006 & 0.009 & 0.007 \\
\hline Geodesic efficiency (E) & 0.171 & 0.15 & 0.214 & 0.171 \\
\hline Harmonic geodesic distance (HD) & 5.861 & 6.687 & 4.679 & 5.85 \\
\hline Maximal degree & 20 & 13 & 21 & 43 \\
\hline Centralization of degree (CD) & 0.042 & 0.023 & 0.048 & 0.087 \\
\hline Centralization of betweenness (CB) & 0.081 & 0.159 & 0.083 & 0.169 \\
\hline Centralization of stress centrality (CS) & 0.357 & 2.258 & 1.133 & 3.413 \\
\hline \multicolumn{5}{|l|}{ Random network } \\
\hline Avg. clustering coefficient & $0.015(0.005)$ & $0.007(0.003)$ & $0.020(0.005)$ & $0.021(0.005)$ \\
\hline Average path distance & $4.619(0.081)$ & $5.309(0.077)$ & $4.202(0.056)$ & $4.332(0.053)$ \\
\hline Avg. modularity & $0.625(0.007)$ & $0.658(0.006)$ & $0.555(0.007)$ & $0.573(0.006)$ \\
\hline
\end{tabular}

(Table 1). The networks showed topological properties of smallworld, scale-free and modularity, and were significantly different from randomly generated networks. The $\mathrm{N}$ addition slightly weakened the inter-connections among fungal species at both sites (Figure 6 and Table 1), with a lower average clustering coefficient (avgCC) and average connectivity degree (avgK), and a higher average path length (APL) and centralization of betweenness (CB). These results indicated that the networks were less clustered in the $\mathrm{N}$ addition treatments. Additionally, positive correlations were predominant in all networks and the number of positive correlations was decreased by $\mathrm{N}$ addition at both sites.

The topological roles of the OTUs identified in the networks were shown as a $\mathrm{Zi}$-Pi plot in Figure 7. The majority of the OTUs were peripherals (also regarded as specialist) with most of their links being inside their modules. A total of 8, 15, 16, and 19 OTUs were classified as module hubs, collectors, and network hubs (putative keystone species) for the four sub-networks (Figure 7 and Supplementary Tables 4-7). The networks in the control and $\mathrm{N}$ addition treatments at the short-term site shared one putative keystone species (OTU140; Eurotiomycetes, Ascomycota), while the networks at the long-term site did not share any keystone species. Most putative keystone species belonged to the classes Eurotiomycetes, Agaricomycetes, Sordariomycetes, Dothideomycetes, Leotiomycetes, Mortierellomycetes, and Tremellomycetes.

\section{DISCUSSION}

\section{Soil Fungal Diversity and Community Composition Were More Sensitive to Short-Term N Addition}

In this study, we used the method of substitution of space for time to assess the duration effects of $\mathrm{N}$ addition on the soil fungal community. We found that the soil fungal $\alpha$-diversity was enhanced by $\mathrm{N}$ addition $\left(\sim 100 \mathrm{~kg} \mathrm{~N} \mathrm{ha}^{-1} \mathrm{yr}^{-1}\right)$ at both the short- and long-term sites (Figures 2A-C), indicating that soil fungi would tend to respond to environmental disturbance by enrichment and domestication (Shi C. et al., 2020; Shi J. et al., 2020). The increased fungal $\alpha$-diversity at both sites may be explained by the following reasons: (i) $\mathrm{N}$ addition enhanced the plant net primary productivity of the tropical forest ( $\mathrm{Du}$ and de Vries, 2018; Liang et al., 2020), leading to more plantderived resources for soil fungal growth; (ii) the rate of $\mathrm{N}$ addition $\left(\sim 100 \mathrm{~kg} \mathrm{~N} \mathrm{ha}^{-1} \mathrm{yr}^{-1}\right)$ likely caused an intermediate disturbance and led to many vacant ecological niches that facilitate fungal colonization, according to the intermediate disturbance hypothesis (Zhang X. et al., 2018); (iii) the internal $\mathrm{pH}$ regulatory mechanism of soil fungi can make their cells maintain a relatively neutral $\mathrm{pH}$ (Gross and Robbins, 2000), and thus, the acidic soil induced by $\mathrm{N}$ addition could result in more abundant acidophilic or acid-tolerant fungi in the 


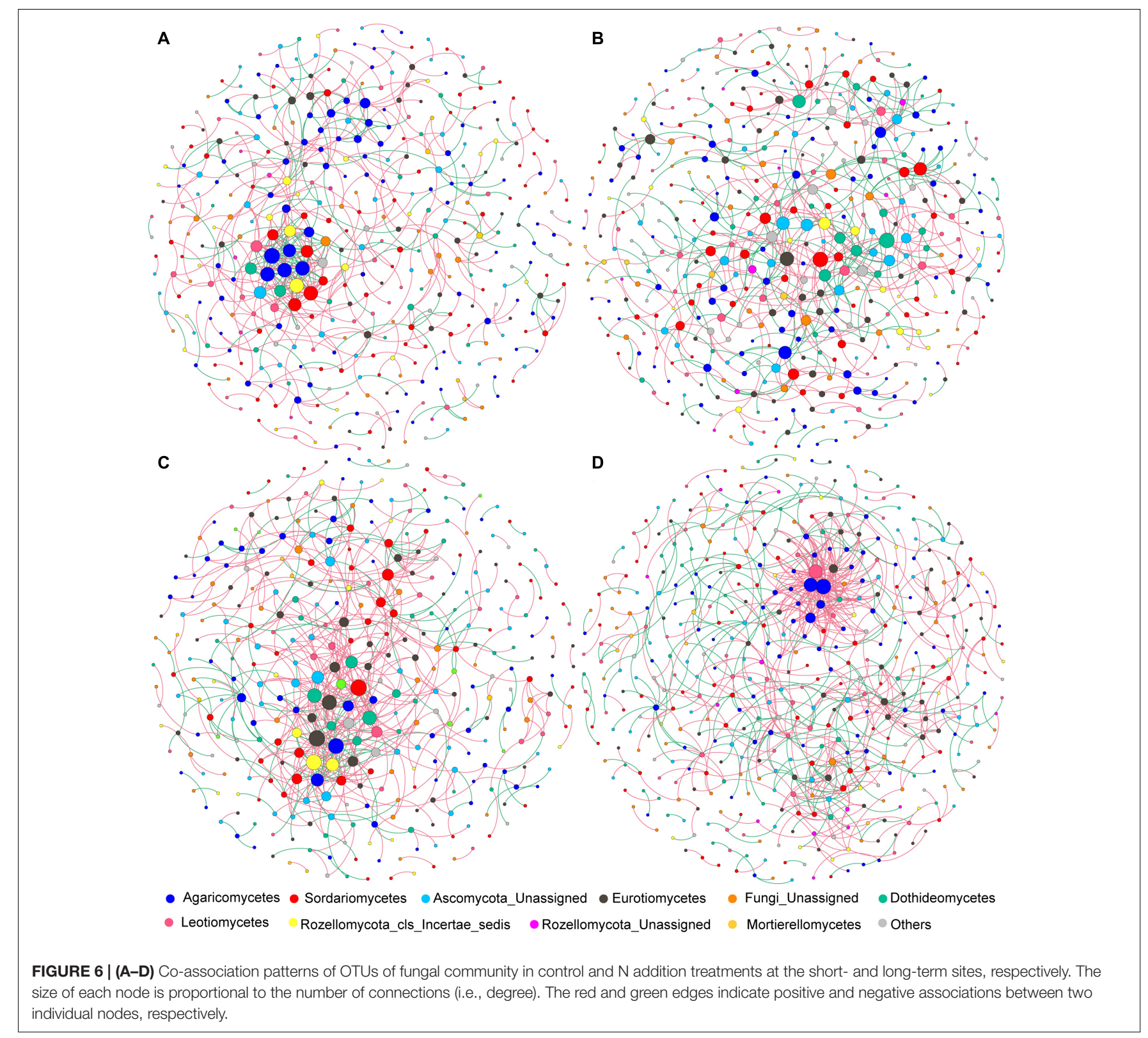

studied forest. However, different response patterns were found in the $\mathrm{N}$-limited temperate and boreal forests, which indicated that soil fungal $\alpha$-diversity or abundance was decreased or not significantly affected by $\mathrm{N}$ addition (Xia et al., 2020; Zhou et al., 2020; He W. et al., 2021). We presume that the discrepancies might originate from the differences in the initial $\mathrm{N}$ status of the forest ecosystems.

Additionally, consistent with our first hypothesis, we observed that $\mathrm{N}$ addition significantly increased the fungal $\alpha$-diversity at the short-term site $(>10 \%)$, but little enhanced at the long-term site ( $<2 \%$; Figures $\mathbf{2 A - C}$ ), suggesting that soil fungal species could be sensitive to short-term $\mathrm{N}$ addition, and may adapt to long-term $\mathrm{N}$ enrichment in the tropical forest. Our results are in line with some of the observations from other forest ecosystems (Entwistle et al., 2013; Zhao et al., 2020). For instance,
Zhao et al. (2020) revealed that 5 years of $\mathrm{N}$ addition increased the fungal $\alpha$-diversity in a mixed deciduous forest; while Entwistle et al. (2013) showed there were no significant effects on fungal $\alpha$-diversity under more than 15 years of $\mathrm{N}$ addition. Different response patterns between short- and long-term $\mathrm{N}$ additions in the present study could be attributed to the sensitivity of fungal species to $\mathrm{N}$ availability. For instance, short-term $\mathrm{N}$ addition significantly increased fungal richness (Figure 2A), suggesting that some rare taxa were stimulated and appeared, while the prolonged $\mathrm{N}$ addition at the long-term site would form a relatively stable fungal community. Moreover, our results were supported by the resistant and resilient abilities of the soil fungal community to environmental disturbance, which indicated that the fungal community could recover to the original state after decades of exogenous $\mathrm{N}$ input (Allison and Martiny, 2008). 
Furthermore, $\mathrm{N}$ addition also altered the fungal community composition between the short- and long-term sites, and the dissimilarities were much greater under short-term than longterm $\mathrm{N}$ addition (Figures 2D,E and Supplementary Figure 3). These dissimilarities of fungal community composition may result from the changes of taxonomic structures. For example, $\mathrm{N}$ addition significantly decreased the relative abundance of Basidiomycota, and increased that of Ascomycota at the shortterm site. Additionally, short-term $\mathrm{N}$ addition also significantly increased the relative abundance of saprotrophic fungi, and decreased that of EcM fungi. However, the relative abundances of these taxa were not significantly impacted by long-term $\mathrm{N}$ addition (Supplementary Figures 1, 2), indicating the durationdependent effects of $\mathrm{N}$ addition on fungal populations. Wang et al. (2019) revealed that $\mathrm{N}$ addition (105 $\mathrm{kg} \mathrm{N}$ ha $^{-1} \mathrm{yr}^{-1}$ ) suppressed the fine root production and turnover at the shortterm site, which would reduce the carbon supply to their associated ectomycorrhizas and decrease the EcM colonization (Corrales et al., 2017). The positive effects of $\mathrm{N}$ addition on relative abundance of saprotrophic fungi may be supported by the "Gadgil effect," in which $\mathrm{N}$ competition between EcM and saprotrophic fungi could benefit to saprotrophic growth (Gadgil and Gadgil, 1971; Fernandez and Kennedy, 2016). Such shifts in fungal community composition could affect the soil enzymatic activities and litter decomposition and, thus, modulate soil $\mathrm{C}, \mathrm{N}$, and $\mathrm{P}$ cycling in forests exposed to atmospheric $\mathrm{N}$ deposition (Ning et al., 2018). Recent studies demonstrated that soil $\mathrm{pH}$ and $\mathrm{NO}_{3}{ }^{-}{ }^{-} \mathrm{N}$ concentration were the key drivers influencing fungal community composition (Francioli et al., 2016; Ullah et al., 2019; Wang et al., 2021). The relative abundance of dominant functional guilds, phyla, and genera (Supplementary Figures 5, 6) was significantly positively or negatively correlated with soil $\mathrm{pH}$ and $\mathrm{NO}_{3}{ }^{-}{ }^{-} \mathrm{N}$ concentration at the short-term site, depending on their preference to $\mathrm{N}$ and tolerance to $\mathrm{pH}$, which also proved the soil fungal community to be sensitive to short-term $\mathrm{N}$ addition. Additionally, the fungal community in $\mathrm{N}$ addition soils had a wider habitat niche breadth than that in control soils at both sites (Supplementary Figure 4), indicating that the fungal community has greater metabolic plasticity and governed less by environmental filtering under $\mathrm{N}$ addition (Wu et al., 2018).

\section{Soil Fungal Community Assembly Was Mainly Shaped by Stochastic Processes}

The significant phylogenetic signals were found across relatively short phylogenetic distances (Figure 4), in line with previous studies on fungal community (Isobe et al., 2019; Yang J. et al., 2020). The results suggested that closely related species exhibited more similar ecological preferences across environmental variations, and fungal responses to $\mathrm{N}$ addition exhibited phylogenetic conservation.

Revealing the assembly rules of the microbial community is a central issue in microbial ecology (Nemergut et al., 2013). Deterministic and stochastic processes are two dominant themes in the study of microbial community dynamics; therefore, it is critical to quantify the relative contributions of the

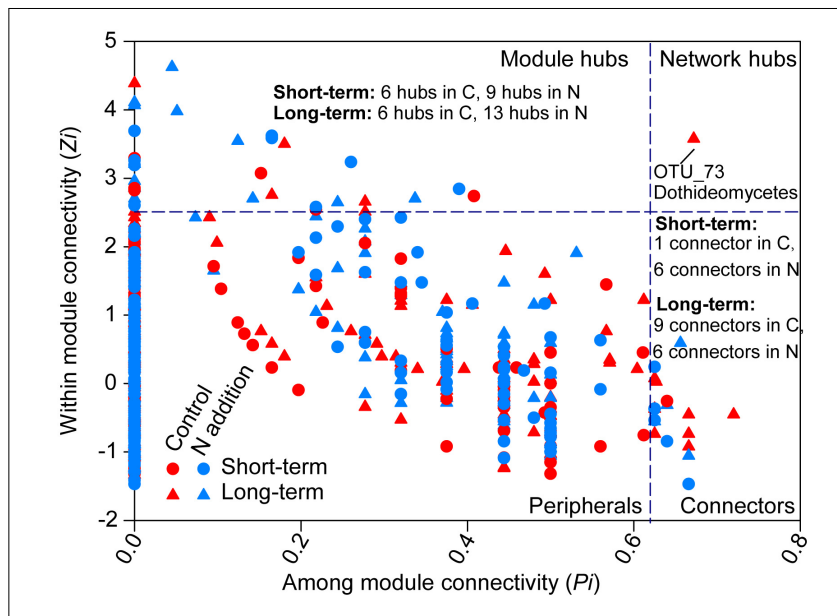

FIGURE 7 | Classification of nodes to identify putative keystone species within the networks. The topological role of each OTU is determined according to the scatter plot of within-module connectivity $(Z i)$ and among-module connectivity $(P i)$. Module hubs have $Z i>2.5$, whereas connectors have $\mathrm{Pi}>0.62$. The number of module hubs and connectors is presented on the plot and the network hub is labeled with the OTU number. The abbreviations of $\mathrm{C}$ and $\mathrm{N}$ are defined as control and $\mathrm{N}$ addition, respectively. Detailed taxonomic information for module hubs and connectors is shown in Supplementary Tables 4-7.

two processes to community assembly (Stegen et al., 2013; Zhou and Ning, 2017). In the present study, the null model and NST analysis consistently showed that stochastic processes were more important than deterministic processes with respect to soil fungal community assembly under control and $\mathrm{N}$ treatments at both sites (Figure 5), which were partially consistent with our second hypothesis. We speculated the short-term $\mathrm{N}$ addition enriched soil nutrients (e.g., $\mathrm{NO}_{3}{ }^{-}-\mathrm{N}$ ), widened the habitat niche breadth of the fungal community, and weakened the effects of environmental filtering. However, the long-term $\mathrm{N}$ addition did not change the soil properties much (Supplementary Table 2), and led to less habitat heterogeneity. This may make a greater relative importance of stochastic events on community composition. Additionally, the hyphal networks of fungi and the roots of their hosts limit the dispersion of fungal species (i.e., dispersal limitation), since most of the dominant trees in the forest are EcM or arbuscular mycorrhizae ( $\mathrm{Lu}$ et al., 2018; Gurmesa et al., 2019). Our results support the view that stochastic processes predominate in the fungal community assembly (Shi et al., 2019; Zhao J. et al., 2019; Jiao and Lu, 2020). Furthermore, the neutral community model explained a relatively large fraction $\left(R^{2}>0.5\right)$ of fungal community variation, indicating that the fungal community was more influenced by neutral (or stochastic) processes.

\section{Co-association Patterns of Fungal Community Under Short- and Long-Term N Additions}

Microorganisms can form complex linkage networks to coexist by occupying specific ecological niches or responding similarly to environments (Faust and Raes, 2012). The co-association 
networks can present new insights into the potential linkage and assembly process of microbial communities under environmental disturbance (Barberán et al., 2012). Nitrogen addition generated looser and more random fungal networks at both sites (Figure 6 and Table 1), indicating that the putative linkage between fungal species were weakened by $\mathrm{N}$ addition. This result supports our third hypothesis that $\mathrm{N}$ addition would alter the fungal network structure. Moreover, network parameters such as avgK and avgCC were higher in control than $\mathrm{N}$ addition, suggesting that higher fungal diversity is not necessarily associated with more complex networks. We speculated that higher fungal diversity in $\mathrm{N}$ addition soils could lead to a higher degree of functional redundancy, which provides more opportunities for fungal species to correlate with their neighbors, as microorganisms tend to interact with each other by function or metabolite preference (Levy and Borenstein, 2013; Tu et al., 2020). As a result, $\mathrm{N}$ addition would lead to weak interspecies linkage and loose coassociation networks of the fungal community. Additionally, positive correlations dominated all the networks (Figure 6), implying that mutual cooperation rather than competitive exclusion played a dominant role in fungal community assembly.

\section{CONCLUSION}

In this study, we compared the variations and responses of fungal taxonomic and phylogenetic $\alpha$-diversity and community composition between two nearby field experiments in a tropical forest which had received short- (2 years) and long-term (13 years) simulated $\mathrm{N}$ deposition $\left(\sim 100 \mathrm{~kg} \mathrm{~N} \mathrm{ha}^{-1} \mathrm{yr}^{-1}\right)$. Our results indicated that fungal $\alpha$-diversity was significantly increased by the short-term $\mathrm{N}$ addition rather than the long-term treatments. Additionally, the variations of fungal $\alpha$-diversity and community composition were greater in short-term compared to long-term $\mathrm{N}$ addition. Soil $\mathrm{pH}$ and $\mathrm{NO}_{3}{ }^{-}-\mathrm{N}$ concentration were the major factors mediating the variations of fungal $\alpha$-diversity and community composition. Stochastic processes played predominant roles in the assembly of the soil fungal community under $\mathrm{N}$ addition at both sites, and the stochasticity was significantly increased by short-term $\mathrm{N}$ addition. Moreover, both short- and long-term $\mathrm{N}$ additions slightly loosened the co-association networks of fungal community. Together, our results revealed that the soil fungal community structure would be sensitive to short-term $\mathrm{N}$ addition, but become adaptive to long-term $\mathrm{N}$ addition. The study will contribute to our

\section{REFERENCES}

Allison, S. D., and Martiny, J. B. H. (2008). Resistance, resilience, and redundancy in microbial communities. Proc. Natl. Acad. Sci. U.S.A. 105, 11512-11519. doi: 10.1073/pnas.0801925105

Baldrian, P., and Valášková, V. (2008). Degradation of cellulose by basidiomycetous fungi. FEMS Microbiol. Rev. 32, 501-521. doi: 10.1111/j.1574-6976.2008. 00106.x

Barberán, A., Bates, S. T., Casamayor, E. O., and Fierer, N. (2012). Using network analysis to explore co-occurrence patterns in soil microbial communities. ISME J. 6, 343-351. doi: 10.1038/ismej.2011.119

Barnes, C. J., van der Gast, C. J., Burns, C. A., McNamara, N. P., and Bending, G. D. (2016). Temporally variable geographical distance effects contribute to understanding of underlying mechanisms that regulate the variations of soil fungal community and facilitate the prediction of fungal responses to the ongoing atmospheric $\mathrm{N}$ deposition in tropical forests.

\section{DATA AVAILABILITY STATEMENT}

All raw sequences from this paper have been submitted to the NCBI Sequence Read Archive (SRA) database under the BioProject number PRJNA664903.

\section{AUTHOR CONTRIBUTIONS}

WS and $\mathrm{JH}$ conceived and designed the study, and wrote the manuscript. JH, XT, HW, XM, and YN were responsible for performing the field and laboratory work. JH and SJ analyzed the data. All authors discussed the results, critically reviewed the manuscript, and approved its publication.

\section{FUNDING}

This study was financially supported by the National Natural Science Foundation of China (31425005, 31290222, and 31400420) and Open Fund of Key Laboratory of Geospatial Technology for the Middle and Lower Yellow River Regions (Henan University), Ministry of Education (GTYR202101).

\section{ACKNOWLEDGMENTS}

We acknowledge the platform support of Dinghushan Forest Ecosystem Research Station, CAS; the assistance we received with field sampling and laboratory assays from Zhuang Ni and Xiaoge Han, Guangcun Hao, and Dan He; and constructive comments to improve the manuscript from the reviewers.

\section{SUPPLEMENTARY MATERIAL}

The Supplementary Material for this article can be found online at: https://www.frontiersin.org/articles/10.3389/fmicb. 2021.689674/full\#supplementary-material

the assembly of root-associated fungal communities. Front. Microbiol. 7:195. doi: 10.3389/fmicb.2016.00195

Bissett, A., Brown, M. V., Siciliano, S. D., and Thrall, P. H. (2013). Microbial community responses to anthropogenically induced environmental change: towards a systems approach. Ecol. Lett. 16, 128-139. doi: 10.1111/ele. 12109

Caruso, T., Chan, Y., Lacap, D. C., Lau, M. C. Y., McKay, C. P., and Pointing, S. B. (2011). Stochastic and deterministic processes interact in the assembly of desert microbial communities on a global scale. ISME J. 5, 1406-1413. doi: 10.1038/ismej.2011.21

Chen, S., Zhou, Y., Chen, Y., and Gu, J. (2018). Fastp: an ultra-fast all-in-one FASTQ preprocessor. Bioinformatics 34, 884-890. doi: 10.1093/bioinformatics/ bty 560 
Chen, Y., Xu, Z., Feng, K., Yang, G., Fu, W., and Chen, B. (2020). Nitrogen and water addition regulate soil fungal diversity and co-occurrence networks. J. Soils Sediments 20, 3192-3203. doi: 10.1007/s11368-020-02629-9

Chen, Y., Xu, Z., Xu, T., Veresoglou, S. D., Yang, G., and Chen, B. (2017). Nitrogen deposition and precipitation induced phylogenetic clustering of arbuscular mycorrhizal fungal communities. Soil Biol. Biochem. 115, 233-242. doi: 10.1016/ j.soilbio.2017.08.024

Corrales, A., Turner, B. L., Tedersoo, L., Anslan, S., and Dalling, J. W. (2017). Nitrogen addition alters ectomycorrhizal fungal communities and soil enzyme activities in a tropical montane forest. Fungal Ecol. 27, 14-23. doi: 10.1016/j. funeco.2017.02.004

Cui, J., Yuan, X., Zhang, Q., Zhou, J., Lin, K., Xu, J., et al. (2021). Nutrient availability is a dominant predictor of soil bacterial and fungal community composition after nitrogen addition in subtropical acidic forests. PLoS One 16:e0246263. doi: 10.1371/journal.pone.0246263

Deng, Y., Jiang, Y., Yang, Y., He, Z., Luo, F., and Zhou, J. (2012). Molecular ecological network analyses. BMC Bioinform. 13:113. doi: 10.1186/1471-210513-113

Dessaux, Y., Grandclément, C., and Faure, D. (2016). Engineering the rhizosphere. Trends Plant Sci. 21, 266-278. doi: 10.1016/j.tplants.2016.01.002

Dini-Andreote, F., Stegen, J. C., van Elsas, J. D., and Salles, J. F. (2015). Disentangling mechanisms that mediate the balance between stochastic and deterministic processes in microbial succession. Proc. Natl. Acad. Sci. U.S.A. 112, 1326-1332. doi: 10.1073/pnas.1414261112

Du, E., and de Vries, W. (2018). Nitrogen-induced new net primary production and carbon sequestration in global forests. Environ. Pollut. 242, 1476-1487. doi: 10.1016/j.envpol.2018.08.041

Entwistle, E. M., Zak, D. R., and Edwards, I. P. (2013). Long-term experimental nitrogen deposition alters the composition of the active fungal community in the forest floor. Soil Sci. Soc. Am. J. 77, 1648-1658. doi: 10.2136/sssaj2013.05. 0179

Faust, K., and Raes, J. (2012). Microbial interactions: from networks to models. Nat. Rev. Microbiol. 10, 538-550. doi: 10.1038/nrmicro2832

Fernandez, C. W., and Kennedy, P. G. (2016). Revisiting the 'Gadgil effect': do interguild fungal interactions control carbon cycling in forest soils? New Phytol. 209, 1382-1394. doi: 10.1111/nph.13648

Francioli, D., Schulz, E., Lentendu, G., Wubet, T., Buscot, F., and Reitz, T. (2016). Mineral vs. organic amendments: microbial community structure, activity and abundance of agriculturally relevant microbes are driven by long-term fertilization strategies. Front. Microbiol. 7:1446. doi: 10.3389/fmicb.2016.01446

Freedman, Z. B., Romanowicz, K. J., Upchurch, R. A., and Zak, D. R. (2015). Differential responses of total and active soil microbial communities to longterm experimental N deposition. Soil Biol. Biochem. 90, 275-282. doi: 10.1016/ j.soilbio.2015.08.014

Gadgil, R. L., and Gadgil, P. D. (1971). Mycorrhiza and litter decomposition. Nature 233, 133-133. doi: 10.1038/233133a0

Galloway, J. N., Dentener, F. J., Capone, D. G., Boyer, E. W., Howarth, R. W., Seitzinger, S. P., et al. (2004). Nitrogen cycles: past, present, and future. Biogeochemistry 70, 153-226. doi: 10.1007/s10533-004-0370-0

Gross, S., and Robbins, E. I. (2000). Acidophilic and acid-tolerant fungi and yeasts. Hydrobiologia 433, 91-109. doi: 10.1023/A:1004014603333

Guimerà, R., and Amaral, L. A. N. (2005). Functional cartography of complex metabolic networks. Nature 433:895. doi: 10.1038/nature03288

Guo, J., Ling, N., Chen, Z., Xue, C., Li, L., Liu, L., et al. (2020). Soil fungal assemblage complexity is dependent on soil fertility and dominated by deterministic processes. New Phytol. 226, 232-243. doi: 10.1111/nph. 16345

Gurmesa, G. A., Lu, X., Gundersen, P., Mao, Q., Fang, Y., and Mo, J. (2019). Species differences in nitrogen acquisition in humid subtropical forest inferred from $15 \mathrm{~N}$ natural abundance and its response to tracer addition. Forests 10:991. doi: 10.3390/f10110991

Han, X., Shen, W., Zhang, J., and Müller, C. (2018). Microbial adaptation to longterm $\mathrm{N}$ supply prevents large responses in $\mathrm{N}$ dynamics and $\mathrm{N}$ losses of a subtropical forest. Sci. Total Environ. 626, 1175-1187. doi: 10.1016/j.scitotenv. 2018.01.132

He, C., Zhang, B., Lu, J., and Qiu, R. (2021). A newly discovered function of nitrate reductase in chemoautotrophic vanadate transformation by natural mackinawite in aquifer. Water Res. 189:116664. doi: 10.1016/j.watres.2020. 116664
He, Q., Wang, S., Hou, W., Feng, K., Li, F., Hai, W., et al. (2021). Temperature and microbial interactions drive the deterministic assembly processes in sediments of hot springs. Sci. Total Environ. 772:145465. doi: 10.1016/j.scitotenv.2021. 145465

He, W., Zhang, M., Jin, G., Sui, X., Zhang, T., and Song, F. (2021). Effects of nitrogen deposition on nitrogen-mineralizing enzyme activity and soil microbial community structure in a Korean pine plantation. Microb. Ecol. 81, 410-424. doi: 10.1007/s00248-020-01595-6

Isobe, K., Allison, S. D., Khalili, B., Martiny, A. C., and Martiny, J. B. H. (2019). Phylogenetic conservation of bacterial responses to soil nitrogen addition across continents. Nat. Commun. 10:, 2499. doi: 10.1038/s41467-019-10390-y

Janssens, I., Dieleman, W., Luyssaert, S., Subke, J. A., Reichstein, M., Ceulemans, R., et al. (2010). Reduction of forest soil respiration in response to nitrogen deposition. Nat. Geosci. 3:315. doi: 10.1038/ngeo844

Jiao, S., and Lu, Y. (2020). Abundant fungi adapt to broader environmental gradients than rare fungi in agricultural fields. Glob. Chang. Biol. 26, 4506-4520. doi: $10.1111 / \mathrm{gcb} .15130$

Levins, R. (1968). Evolution in Changing Environments: Some Theoretical Explorations. Princeton, NJ: Princeton University Press.

Levy, R., and Borenstein, E. (2013). Metabolic modeling of species interaction in the human microbiome elucidates community-level assembly rules. Proc. Natl. Acad. Sci. U.S.A. 110, 12804-12809. doi: 10.1073/pnas.1300926110

Li, J., Zheng, Y., Liu, Y., Ma, Y., Hu, H., and He, J. (2014). Initial copper stress strengthens the resistance of soil microorganisms to a subsequent copper stress. Microb. Ecol. 67, 931-941. doi: 10.1007/s00248-014-0391-8

Li, S., Li, Y., Hu, C., Zheng, X., Zhang, J., Zhang, H., et al. (2021). Stochastic processes drive bacterial and fungal community assembly in sustainable intensive agricultural soils of Shanghai, China. Sci. Total Environ. 778:146021. doi: 10.1016/j.scitotenv.2021.146021

Liang, X., Zhang, T., Lu, X., Ellsworth, D. S., BassiriRad, H., You, C., et al. (2020). Global response patterns of plant photosynthesis to nitrogen addition: a meta-analysis. Glob. Chang. Biol. 26, 3585-3600. doi: 10.1111/gcb.15071

Lu, M., Yang, Y., Luo, Y., Fang, C., Zhou, X., Chen, J., et al. (2011). Responses of ecosystem nitrogen cycle to nitrogen addition: a meta-analysis. New Phytol. 189, 1040-1050. doi: 10.1111/j.1469-8137.2010.03563.x

Lu, X., Vitousek, P. M., Mao, Q., Gilliam, F. S., Luo, Y., Zhou, G., et al. (2018). Plant acclimation to long-term high nitrogen deposition in an N-rich tropical forest. Proc. Natl. Acad. Sci. U.S.A. 115, 5187-5192. doi: 10.1073/pnas.1720777115

Martin, M. (2011). Cutadapt removes adapter sequences from high-throughput sequencing reads. EMBnet J. 17, 10-12. doi: 10.14806/ej.17.1.200

Mo, J., Brown, S., Xue, J., Fang, Y., and Li, Z. (2006). Response of litter decomposition to simulated $\mathrm{N}$ deposition in disturbed, rehabilitated and mature forests in subtropical China. Plant Soil 282, 135-151. doi: 10.1007/ s11104-005-5446-7

Morrison, E. W., Frey, S. D., Sadowsky, J. J., van Diepen, L. T. A., Thomas, W. K., and Pringle, A. (2016). Chronic nitrogen additions fundamentally restructure the soil fungal community in a temperate forest. Fungal Ecol. 23, 48-57. doi: 10.1016/j.funeco.2016.05.011

Nemergut, D. R., Schmidt, S. K., Fukami, T., O’Neill, S. P., Bilinski, T. M., Stanish, L. F., et al. (2013). Patterns and processes of microbial community assembly. Microbiol. Mol. Biol. Rev. 77, 342-356. doi: 10.1128/MMBR.00051-12

Nguyen, N. H., Song, Z., Bates, S. T., Branco, S., Tedersoo, L., Menke, J., et al. (2016). FUNGuild: an open annotation tool for parsing fungal community datasets by ecological guild. Fungal Ecol. 20, 241-248. doi: 10.1016/j.funeco. 2015.06.006

Ning, C., Mueller, G. M., Egerton-Warburton, L. M., Wilson, A. W., Yan, W., and Xiang, W. (2018). Diversity and enzyme activity of ectomycorrhizal fungal communities following nitrogen fertilization in an urban-adjacent pine plantation. Forests 9:99. doi: 10.3390/f9030099

Ning, D., Deng, Y., Tiedje, J. M., and Zhou, J. (2019). A general framework for quantitatively assessing ecological stochasticity. Proc. Natl. Acad. Sci. U.S.A. 116, 16892-16898. doi: 10.1073/pnas.1904623116

Schneider, T., Keiblinger, K. M., Schmid, E., Sterflinger-Gleixner, K., Ellersdorfer, G., Roschitzki, B., et al. (2012). Who is who in litter decomposition? Metaproteomics reveals major microbial players and their biogeochemical functions. ISME J. 6, 1749-1762. doi: 10.1038/ismej.2012.11

Shi, C., Cui, Y., Lu, J., and Zhang, B. (2020). Sulfur-based autotrophic biosystem for efficient vanadium (V) and chromium (VI) reductions in groundwater. Chem. Eng. J. 395:124972. doi: 10.1016/j.cej.2020.1 
Shi, J., Zhang, B., Cheng, Y., and Peng, K. (2020). Microbial vanadate reduction coupled to co-metabolic phenanthrene biodegradation in groundwater. Water Res. 186:116354. doi: 10.1016/j.watres.2020.116354

Shi, Y., Dang, K., Dong, Y., Feng, M., Wang, B., Li, J., et al. (2019). Soil fungal community assembly processes under long-term fertilization. Eur. J. Soil Sci. 71, 716-726. doi: 10.1111/ejss.12902

Sloan, W. T., Lunn, M., Woodcock, S., Head, I. M., Nee, S., and Curtis, T. P. (2006). Quantifying the roles of immigration and chance in shaping prokaryote community structure. Environ. Microbiol. 8, 732-740. doi: 10.1111/j.1462-2920. 2005.00956.x

Stegen, J. C., Lin, X., Fredrickson, J. K., Chen, X., Kennedy, D. W., Murray, C. J., et al. (2013). Quantifying community assembly processes and identifying features that impose them. ISME J. 7, 2069-2079. doi: 10.1038/ismej.2013.93

Stegen, J. C., Lin, X., Fredrickson, J. K., and Konopka, A. E. (2015). Estimating and mapping ecological processes influencing microbial community assembly. Front. Microbiol. 6:370. doi: 10.3389/fmicb.2015.00370

Stegen, J. C., Lin, X., Konopka, A. E., and Fredrickson, J. K. (2012). Stochastic and deterministic assembly processes in subsurface microbial communities. ISME J. 6, 1653-1664. doi: 10.1038/ismej.2012.22

Tedersoo, L., Bahram, M., and Zobel, M. (2020). How mycorrhizal associations drive plant population and community biology. Science 367:eaba1223. doi: 10 . 1126/science.aba1223

Tu, Q., Yan, Q., Deng, Y., Michaletz, S. T., Buzzard, V., Weiser, M. D., et al. (2020). Biogeographic patterns of microbial co-occurrence ecological networks in six American forests. Soil Biol. Biochem. 148:107897. doi: 10.1016/j.soilbio.2020. 107897

Ullah, S., Ai, C., Ding, W., Jiang, R., Zhao, S., Zhang, J., et al. (2019). The response of soil fungal diversity and community composition to long-term fertilization. Appl. Soil Ecol. 140, 35-41. doi: 10.1016/j.apsoil.2019.03.025

Vellend, B. M. (2010). Conceptual synthesis in community ecology. Q. Rev. Biol. 85, 183-206. doi: 10.1086/652373

Wang, C., Lu, X., Mori, T., Mao, Q., Zhou, K., Zhou, G., et al. (2018). Responses of soil microbial community to continuous experimental nitrogen additions for 13 years in a nitrogen-rich tropical forest. Soil Biol. Biochem 121, 103-112. doi: 10.1016/j.soilbio.2018.03.009

Wang, J., Shi, X., Zheng, C., Suter, H., and Huang, Z. (2021). Different responses of soil bacterial and fungal communities to nitrogen deposition in a subtropical forest. Sci. Total Environ. 755:142449. doi: 10.1016/j.scitotenv.2020.142449

Wang, W., Mo, Q., Han, X., Hui, D., and Shen, W. (2019). Fine root dynamics responses to nitrogen addition depend on root order, soil layer, and experimental duration in a subtropical forest. Biol. Fertil. Soils 55, 723-736. doi: 10.1007/s00374-019-01386-3

Weese, D. J., Heath, K. D., Dentinger, B. T. M., and Lau, J. A. (2015). Long-term nitrogen addition causes the evolution of less-cooperative mutualists. Evolution 69, 631-642. doi: 10.1111/evo.12594

Wei, C., Yu, Q., Bai, E., Lü, X., Li, Q., Xia, J., et al. (2013). Nitrogen deposition weakens plant-microbe interactions in grassland ecosystems. Glob. Chang. Biol. 19, 3688-3697. doi: 10.1111/gcb.12348

Wen, Z., Xu, W., Li, Q., Han, M., Tang, A., Zhang, Y., et al. (2020). Changes of nitrogen deposition in China from 1980 to 2018. Environ. Int. 144:106022. doi: $10.1016 /$ j.envint.2020.106022

White, T. J., Bruns, T., Lee, S., and Taylor, J. (1990). "Amplification and direct sequencing of fungal ribosomal RNA genes for phylogenetics," in PCR Protocols: A Guide to Methods and Applications, eds M. A. Innis, D. H. Gelfand, J. J. Sninsky, and T. J. White (New York, NY: Academic Press), 315-322. doi: 10. 1016/b978-0-12-372180-8.50042-1

Wu, W., Lu, H., Sastri, A., Yeh, Y. C., Gong, G. C., Chou, W. C., et al. (2018). Contrasting the relative importance of species sorting and dispersal limitation in shaping marine bacterial versus protist communities. ISME J. 12, 485-494. doi: 10.1038/ismej.2017.183

Xia, Z., Yang, J., Sang, C., Wang, X., Sun, L., Jiang, P., et al. (2020). Phosphorus reduces negative effects of nitrogen addition on soil microbial communities and functions. Microorganisms 8:1828. doi: 10.3390/microorganisms8111828

Yan, G., Wang, Q., Zhang, J., Liu, G., Wang, L., Huang, B., et al. (2021). Long-term nitrogen addition and reduced precipitation restructure soil fungal community in a temperate forest. Scand. J. For. Res. 36, 1-12. doi: 10.1080/02827581.2021. 1890206
Yang, J., Jiang, H., Sun, X., Chen, J., Xie, Z., and Dong, H. (2020). Minerals play key roles in driving prokaryotic and fungal communities in the surface sediments of the Qinghai-Tibetan lakes. FEMS Microbiol. Ecol. 96:fiaa035. doi: 10.1093/femsec/fiaa035

Yang, X., Ma, L., Ji, L., Shi, Y., Yi, X., Yang, Q., et al. (2019). Long-term nitrogen fertilization indirectly affects soil fungi community structure by changing soil and pruned litter in a subtropical tea (Camellia sinensis L.) plantation in China. Plant Soil 444, 409-426. doi: 10.1007/s11104-01904291-8

Yang, Y., Cheng, H., Gao, H., and An, S. (2020). Response and driving factors of soil microbial diversity related to global nitrogen addition. Land Degrad. Dev. 31, 190-204. doi: 10.1002/ldr.3439

Yu, G., Jia, Y., He, N., Zhu, J., Chen, Z., Wang, Q., et al. (2019). Stabilization of atmospheric nitrogen deposition in China over the past decade. Nat. Geosci. 12, 424-429. doi: 10.1038/s41561-019-0352-4

Zhang, H., Wang, L., Liu, H., Zhao, J., Li, G., Wang, H., et al. (2018). Nitrogen deposition combined with elevated precipitation is conducive to maintaining the stability of the soil fungal diversity on the Stipa baicalensis steppe. Soil Biol. Biochem. 117, 135-138. doi: 10.1016/j.soilbio.2017. 11.004

Zhang, X., Johnston, E. R., Barberán, A., Ren, Y., Wang, Z., and Han, X. (2018). Effect of intermediate disturbance on soil microbial functional diversity depends on the amount of effective resources. Environ. Microbiol. 20, 38623875. doi: 10.1111/1462-2920.14407

Zhao, A., Liu, L., Chen, B., Fu, W., Xie, W., Xu, T., et al. (2020). Soil fungal community is more sensitive to nitrogen deposition than increased rainfall in a mixed deciduous forest of China. Soil Ecol. Lett. 2, 20-32. doi: 10.1007/s42832020-0026-6

Zhao, J., Gao, Q., Zhou, J., Wang, M., Liang, Y., Sun, B., et al. (2019). The scale dependence of fungal community distribution in paddy soil driven by stochastic and deterministic processes. Fungal Ecol. 42:100856. doi: 10.1016/j.funeco.2019. 07.010

Zhao, Z., He, J., Geisen, S., Han, L., Wang, J., Shen, J., et al. (2019). Protist communities are more sensitive to nitrogen fertilization than other microorganisms in diverse agricultural soils. Microbiome 7:33. doi: 10.1186/ s40168-019-0647-0

Zhou, J., Deng, Y., Luo, F., He, Z., and Yang, Y. (2011). Phylogenetic molecular ecological network of soil microbial communities in response to elevated $\mathrm{CO} 2$. mBio 2:e00122-11. doi: 10.1128/mBio.00122-11

Zhou, J., and Ning, D. (2017). Stochastic community assembly: does it matter in microbial ecology? Microbiol. Mol. Biol. Rev. 81, e2-e17. doi: 10.1128/MMBR. 00002-17

Zhou, K., Lu, X., Mori, T., Mao, Q., Wang, C., Zheng, M., et al. (2018). Effects of long-term nitrogen deposition on phosphorus leaching dynamics in a mature tropical forest. Biogeochemistry 138, 215-224. doi: 10.1007/s10533-0180442-1

Zhou, Z., Wang, C., and Luo, Y. (2020). Meta-analysis of the impacts of global change factors on soil microbial diversity and functionality. Nat. Commun. 11:3072. doi: 10.1038/s41467-020-16881-7

Conflict of Interest: The authors declare that the research was conducted in the absence of any commercial or financial relationships that could be construed as a potential conflict of interest.

Publisher's Note: All claims expressed in this article are solely those of the authors and do not necessarily represent those of their affiliated organizations, or those of the publisher, the editors and the reviewers. Any product that may be evaluated in this article, or claim that may be made by its manufacturer, is not guaranteed or endorsed by the publisher.

Copyright ( $2021 \mathrm{He}$, Jiao, Tan, Wei, Ma, Nie, Liu, Lu, Mo and Shen. This is an open-access article distributed under the terms of the Creative Commons Attribution License (CC BY). The use, distribution or reproduction in other forums is permitted, provided the original author(s) and the copyright owner(s) are credited and that the original publication in this journal is cited, in accordance with accepted academic practice. No use, distribution or reproduction is permitted which does not comply with these terms. 